\title{
Antidepressant-like effect of Ikwitang involves modulation of monoaminergic systems
}

\author{
HEE-YUN KIM ${ }^{1}$, HYUN-JA JEONG ${ }^{2}$ and HYUNG-MIN KIM ${ }^{1}$ \\ ${ }^{1}$ Department of Pharmacology, College of Korean Medicine, Kyung Hee University, Seoul 130-701; \\ ${ }^{2}$ Department of Food Technology, Inflammatory Disease Research Center, \\ Hoseo University, Asan, Chungnam 336-795, Republic of Korea
}

Received February 13, 2015; Accepted December 15, 2015

DOI: $10.3892 / \mathrm{mmr} .2016 .4809$

\begin{abstract}
Depression is a chronic mental disorder. Inflammatory reactions have an important function in the pathophysiology of depression. Ikwitang (IW) has been used to treat fever and inflammatory diseases, however, its effect on depression has not been previously investigated. Therefore, the present study evaluated the possible antidepressant-like effect of IW using a forced swimming test (FST) in mice. IW was orally administered for 14 days. On the 14 day, IW was administered $1 \mathrm{~h}$ prior to the FST. The immobility durations of the IW groups $(0.01,0.1$ and $1 \mathrm{~g} / \mathrm{kg}$ ) were significantly decreased, compared with those of the distilled water (D.W.) groups. The reduction of immobility duration by IW was associated with significant increases in the levels of serotonin, noradrenaline and estrogen receptor- $\beta$ in the brain. IW significantly increased the levels of brain-derived neurotrophic factor and phosphorylated extracellular signal-regulated kinases, compared with the D.W. groups. In addition, the levels of inflammatory cytokines were significantly reduced following IW administration in the hippocampus and serum. In conclusion, the results of the present study suggested that the antidepressant effect of IW may be associated with the modulation of monoaminergic systems and inflammatory reactions.
\end{abstract}

Correspondence to: Professor Hyun-Ja Jeong, Department of Food Technology, Inflammatory Disease Research Center, Hoseo University, 20, Hoseo-ro, 79 Beon-gil, Baebang-eup, Asan, Chungnam 336-795, Republic of Korea

E-mail: hjjeong@hoseo.edu

Professor Hyung-Min Kim, Department of Pharmacology, College of Korean Medicine, Kyung Hee University, 26 Kyungheedae-ro, Dongdaemun-gu, Seoul 130-701, Republic of Korea

E-mail:hmkim@khu.ac.kr

Key words: depression, Ikwitang, forced swimming test, serotonin, brain-derived neurotrophic factor

\section{Introduction}

Almost all individuals suffer from a form of psychological and physical stress, and increased stress can lead to other health complications. In particular, depression is a chronic mental disorder that causes, not only psychological and physical damage, but is also associated with suicide rates $(1,2)$. Antidepressants in current use include monoamine oxidase inhibitors, norepinephrine (NE) reuptake inhibitors, selective serotonin (5'hydroxytryptamine; 5HT) reuptake inhibitors, tricyclic antidepressants, 5HT and noradrenaline (NA) reuptake inhibitors, and NA and dopamine reuptake inhibitors (3). Although these antidepressant drugs show adequate potency, they frequently produce unwanted adverse effects. Therefore, there has been a focus on identifying and developing more promising antidepressants through the use of alternative medicine (4).

Monoaminergic systems have a central function in neuronal system (5). Phytoestrogens, which selectively bind estrogen receptor (ER)- $\beta$ have been shown to improve mood and 5HT neurotransmission (3). 5HT induces the significant increase in the expression of hippocampal brain-derived neurotrophic factor (BDNF) (6). BDNF is a member of the neurotrophin family, and improves the development and function of several neuronal systems (7). In addition, BDNF promotes neuronal cell growth and protects against hippocampal damage in depression (7). These BDNFs are expressed via the activation of extracellular signal-regulated kinases (ERKs) (8).

The inflammatory hypothesis of depression suggests that elevated circulating levels of pro-inflammatory cytokines promote the evolution and maintenance of depressive symptoms (9). Ikwitang (IW) is has been used for the treatment of inflammatory diseases (10). IW is composed of Liriopis Tuber, Rehmanniae Radix, Adenophorae Radix, Rhizoma Polygonati odorati, and Saccharum nigrum. Liriopis Tuber reduces hyper-responsiveness and airway inflammation (11). Rehmanniae Radix has been used in the treatment of depression in several Asian countries (12). Adenophorae Radix has regulatory effects on airway inflammation and hyper-responsiveness (13). However, the effects of IW on depression remain to be elucidated. The present study aimed to investigate the antidepressant-like effect of IW, and to determine the regulatory mechanisms of IW in the central monoaminergic system. 
The present study investigated if IW exhibited antidepressant-like effects though the modulation of monoaminergic systems.

\section{Materials and methods}

Reagents. Avidin peroxidase, bicinchoninic acid (BCA), and other reagents were purchased from Sigma-Aldrich (St. Louis, MO, USA). Anti-mouse interleukin (IL)-1 $\beta$, IL- 6 and tumor necrosis factor (TNF)- $\alpha$ purified antibody $(\mathrm{Ab})$, anti-mouse IL- 6 , TNF- $\alpha$ and IL- $1 \beta$ biotin-conjugated $A b$, and recombinant mouse (rm) IL-1 $\beta$, IL- 6 and TNF- $\alpha$ Ab were purchased from BD Pharmingen (San Diego, CA, USA). Abs for BDNF, GAPDH, ERK and phosphorylated ERK (pERK) were obtained from Santa Cruz Biotechnology, Inc. (Santa Cruz, CA, USA).

Preparation of $I W$. A sample of IW was obtained from an oriental drug store, Noa Pharmacy (Seoul, South Korea), and then authenticated by Professor HM Kim, College of Korean Medicine, Kyung Hee University (Seoul, South Korea). A voucher specimen was deposited at the College of Korean Medicine, Kyung Hee University (IW voucher no. 304047). IW was extracted by decocting the dried herbs (total $58.125 \mathrm{~g}$ ) with boiling distilled water (D.W; 1 liter) for $\sim 2.5$ h. The decoction was then filtered using $3 \mathrm{MM}$ chromatography paper, lyophilized in a freeze-dryer (Operon Co., Ltd., Kimpo, South Korea) and stored at $4^{\circ} \mathrm{C}$. An IW yield of $9.7 \%$ was obtained by freeze-drying. IW was dissolved in D.W. IW was filtered through a $0.22 \mu \mathrm{m}$ syringe filter and then diluted with D.W. ( 1 and $10 \mathrm{mg} / \mathrm{ml}$ ). The dose range of $0.01,0.1$ and $1 \mathrm{~g} / \mathrm{kg}$ was selected to determine whether dose dependency was apparent, in accordance with a previous report (9).

Forced swimming test (FST). Male ICR mice (3 weeks old, 10-12 g) were purchased from the Dae-Han Experimental Animal Center (Daejon, South Korea), and subsequently housed at the College of Korean Medicine, Kyung Hee University. The animals were maintained at a temperature of $22 \pm 1^{\circ} \mathrm{C}$ at a relative humidity of $55 \pm 10 \%$ under a 12:12 light/dark cycle, lights on at 7:00 throughout the study. Food and water were available ad libitum. All manipulations were carried out between 9:00 and 16:00, and no animal was used more than once. All protocols were approved by the institutional animal care and use committee of Kyung Hee University (Seoul, South Korea). Following the first measurement of immobility times, the mice were randomly separated into control, fluoxetine and IW ( 0.01 , 0.1 and $1 \mathrm{~g} / \mathrm{kg}$ ) groups, based on the documented immobility times. IW $(0.01,0.1$, and $1 \mathrm{~g} / \mathrm{kg})$ was orally administered to mice once per day for 2 weeks using an atraumatic feeding needle. Fluoxetine $(10 \mathrm{mg} / \mathrm{kg})$, an antidepressant of the selective serotonin reuptake inhibitor class, was used as a positive control. The FST was performed at the end of the 2-week administration period. During the 6 min FST, the times of immobility was measured. The instrument comprised two Plexiglas cylinders (height, $25 \mathrm{~cm}$; diameter, $10 \mathrm{~cm}$; Deoksan Lab, Seoul, South Korea), placed alongside a Makrolon cage (Dae-Han Experimental Animal Center) filled with water (10 cm height) at a temperature of $23-25^{\circ} \mathrm{C}$. For the FST, two mice (one from each experimental group) were assessed concurrently for a 6 min period of time inside the vertical Plexiglas cylinders. An opaque screen was placed between the two cylinders to prevent the mice from seeing each other. The total duration of immobility, following a stabilizing duration of $2 \mathrm{~min}$, was measured for a period of $4 \mathrm{~min}$. Each mouse was considered to be immobile when it ceased struggling and remained floating motionless in the water, making only those movements necessary to maintain its head above the water surface. Each group contained five mice. Mice were anesthetized using an intraperitoneal injection of ketamine $(80 \mathrm{mg} / \mathrm{kg})$ and xylazine $(4 \mathrm{mg} / \mathrm{kg})$. Following anesthetization, blood was withdrawn from the hearts of forced swimming-tested mice. Then, the serum was prepared by centrifugation at $1,900 \mathrm{x} \mathrm{g}$ at $4^{\circ} \mathrm{C}$ for $10 \mathrm{~min}$. The hippocampus was dissected out of the brain and homogenized with a homogenization buffer $(20 \mathrm{mM}$ HEPES pH 7.5, $1.5 \mathrm{mM} \mathrm{MgCl}_{2}, 0.2 \mathrm{mM}$ EDTA, $0.1 \mathrm{M} \mathrm{NaCl}$, $0.2 \mathrm{mM}$ DTT). The protein extracts were prepared by centrifugation at $12,000 \mathrm{xg}$ for $10 \mathrm{~min}$ at $4^{\circ} \mathrm{C}$.

5HT assay. The 5HT levels were measured, according to the manufacturer protocol using a Mouse 5HT/ST ELISA kit (MyBiosource, San Diego, CA, USA).

NA assay. The NA levels were measured according to manufacturer protocol using an NA Urine ELISA kit (Labor Diagnostika Nord GmbH \& Co. KG, Nordhorn, Germany).

Reverse transcription-quantitative polymerase chain reaction $(R T-q P C R)$. Total RNA was isolated from tissue according to the manufacturer's specification using easy-BLUE RNA extraction kit (iNtRON Biotechnology, Inc., Kyungki-Do, South Korea). The concentration of total RNA in the final elutes was determined by NanoDrop (Thermo Fisher Scientific, Inc., Waltham, MA, USA). Total RNA (2.5 $\mu \mathrm{g})$ was heated at $65^{\circ} \mathrm{C}$ for $10 \mathrm{~min}$ and then chilled on ice. Each sample was reverse-transcribed to cDNA for $90 \mathrm{~min}$ at $37^{\circ} \mathrm{C}$ using First-Strand cDNA Synthesis kit (GE Healthcare Life Sciences, Chalfont, UK). RT-qPCR was performed using SYBR Green master mix (Applied Biosystems; Thermo Fisher Scientific, Inc.), and the detection of mRNA was analyzed using an ABI Step One real time PCR system (Applied Biosystems; Thermo Fisher Scientific, Inc.). Primer sequences for the reference gene, GAPDH, and the genes of interest were as follows: GAPDH, forward 5'-TCGACAGTCAGCCGC ATC TTCTTT-3' and reverse 5'-ACCAAATCCGTTGACTCCGAC CTT-3'; estrogen receptor (ER)- $\beta$, forward 5'-GACTGTAGA ACGGTGTGGTC-3' and reverse 5'-CCTGTG AGGTAGGAA TGCGA 3'); IL-6, forward 5'-AAATTCGGTACATCC TCG ACGGCA-3' and reverse 5'-AGTGCCTCTTTGCTGCTT TCACAC-3'); TNF- $\alpha$, forward 5'-AGGACGAACATCCAA CCTTCCCAA-3' and reverse 5'-TTTGAGCCAGAAGAG GTTGAGGGT-3'); IL-1 $\beta$, forward 5'-AAA CAGATGAAG TGCTCCTT-3' and reverse 5'-TGGAGAACACCACTT GTT GC-3'. These were obtained from the Bioneer Corporation, Daejeon, South Korea. The thermocycling profile used was as follows: Initial step of $95^{\circ} \mathrm{C}$ for $10 \mathrm{~min}$, followed by $95^{\circ} \mathrm{C}$ for $15 \mathrm{sec}$ and $60^{\circ} \mathrm{C}$ for $30 \mathrm{sec}$, for 40 cycles, prior to melting curve analysis. The levels of target mRNA were normalized to the level of GAPDH and compared with the control. Data were analyzed using the $2^{-\Delta \Delta C q}$ method (14). 
A

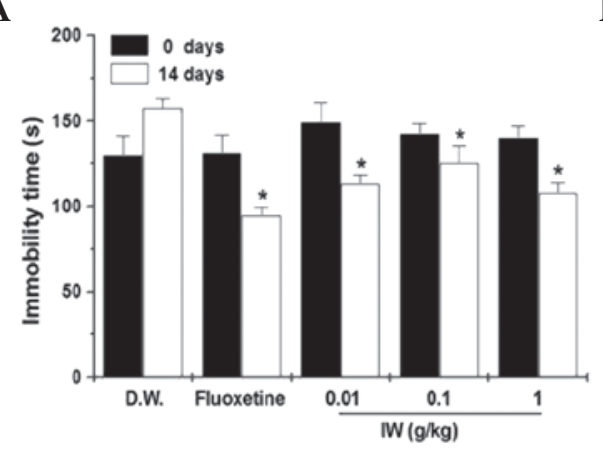

B

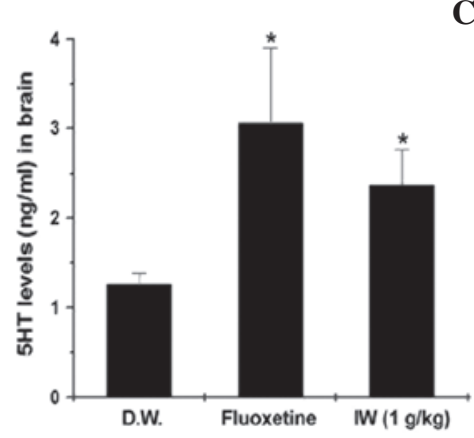

C

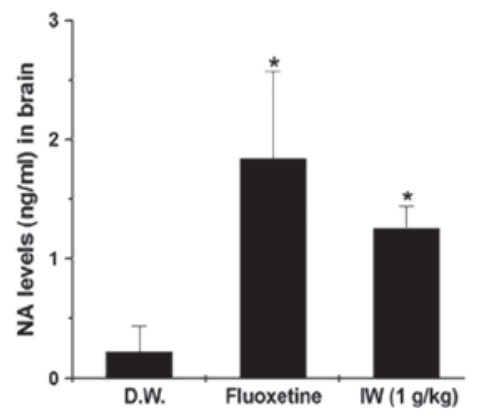

Figure 1. Effect of IW on the immobility time (duration), and the levels of 5HT and NA. IW or fluoxetine was administered 1 h prior to the FST. (A) Immobility times (duration). Following the final FST, the levels of (B) 5HT and (C) NA in the brain were measured using assay kits. Values are expressed as the mean \pm standard error of the mean. ${ }^{*} \mathrm{P}<0.05$, vs. D.W. control group. FST, forced swimming test; IW, Ikwitang; D.W., distilled water; 5HT, 5'hydroxytryptamine; NA, noradrenaline.

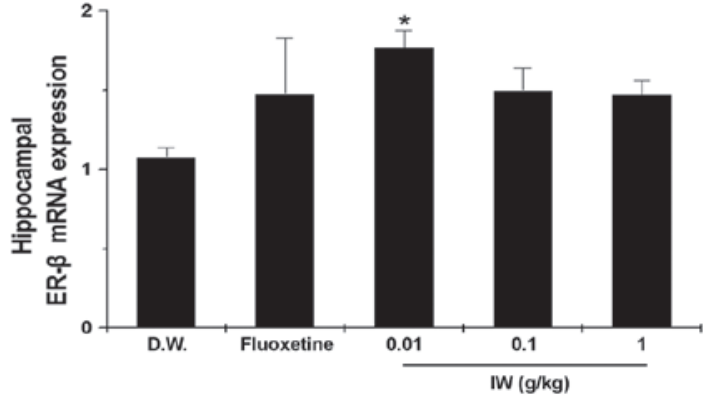

Figure 2. Effect of IW on the hippocampal mRNA expression of ER- $\beta$. The mRNA expression levels of ER- $\beta$ in the hippocampus was measured using reverse transcription-quantitative polymerase chain reaction analysis. Values are expressed as the mean \pm standard error of the mean. ${ }^{*} \mathrm{P}<0.05$ vs. D.W. control group. IW, Ikwitang; D.W., distilled water; ER- $\beta$, estrogen receptor- $\beta$.

Western blot analysis. Hippocampus tissue extracts were used for Western blot analysis. Western blotting was performed, as previously described. Samples were heated at $95^{\circ} \mathrm{C}$ for $5 \mathrm{~min}$ and briefly cooled on ice. Following the centrifugation, protein was estimated using a Pierce BCA Protein Assay kit (Thermo Fisher Scientific, Inc.). The $50 \mu \mathrm{g}$ aliquots were resolved by $12 \%$ sodium dodecyl sulfate-polyacrylamide gel electrophoresis at $120 \mathrm{~V}$ for $2 \mathrm{~h}$. The resolved proteins were electro-transferred overnight to nitrocellulose membranes in $25 \mathrm{mM}$ Tris, $\mathrm{pH} 8.5$, $200 \mathrm{mM}$ glycerin, and $20 \%$ methanol at $20 \mathrm{~V}$. Blots were blocked for at least $2 \mathrm{~h}$ with $6 \%$ bovine serum albumin then incubated with rabbit polyclonal anti-mouse BDNF (1:500, sc-546), mouse monoclonal anti-mouse GAPDH (1:500, sc-32233), rabbit polyclonal anti-mouse ERK (1:500, sc-94), and mouse monoclonal anti-mouse pERK (1:500, sc-7383) Abs for $1 \mathrm{~h}$ at room temperature. The membranes were washed three times with phosphate-buffered saline containing $0.05 \%$ Tween-20. Blots were developed by peroxidase-conjugated rabbit/mouse secondary Abs (1:5,000, Santa Cruz, CA, USA) for $30 \mathrm{~min}$, and proteins were visualized by enhanced chemiluminescence procedures (GE Healthcare Life Sciences), according to the manufacturer's protocol.

Enzyme-linked immunosorbent assay (ELISA). The levels of cytokines in the serum and in the hippocampal tissues were analyzed using an ELISA. The ELISA was performed, as described previously (10). The 96-well plates used were coated with $100 \mu \mathrm{l}$ aliquots of anti-mouse IL-1 $\beta / \mathrm{IL}-6 / \mathrm{TNF}-\alpha$ monoclonal antibodies at a concentration of $1.0 \mu \mathrm{g} / \mathrm{ml}$ in PBS, respectively and incubated overnight at $4^{\circ} \mathrm{C}$. Following 3 washes with PBS containing $0.05 \%$ Tween (PBST), $100 \mu 1$ of samples or IL-1 $\beta / \mathrm{IL}-6 / \mathrm{TNF}-\alpha$ standards were added and incubated at $37^{\circ} \mathrm{C}$ for $2 \mathrm{~h}$. The wells were washed 3 times with PBST and biotinylated anti-mouse IL-1 $\beta / \mathrm{IL}-6 / \mathrm{TNF}-\alpha$ antibodies $(1 \mu \mathrm{g} / \mathrm{ml})$ were added and incubated at $37^{\circ} \mathrm{C}$ for an additional $2 \mathrm{~h}$. Next, the wells were washed 3 times with PBST and the avidin-peroxidase was added and incubated for $30 \mathrm{~min}$ at $37^{\circ} \mathrm{C}$. The wells were then washed with PBST, and a substrate solution was added. The plates were read at $405 \mathrm{~nm}$. Cytokine levels in the hippocampus were divided according to the total protein levels, which were estimated using a Pierce BCA protein assay kit (Thermo Fisher Scientific, Inc.).

Statistical analysis. Data are expressed as the mean \pm standard error of the mean. The analyses were performed using SPSS v. 11.5 (SPSS, Inc., Chicago, IL, USA). P<0.05 was considered to indicate a statistically significant difference. Comparison between the effects of different treatments were analyzed using an independent $t$-test and one-way analysis of variance, followed by Tukey's multiple range tests

\section{Results}

Effect of IW on immobility duration in the FST. The IW (0.01, 0.1 and $1 \mathrm{~g} / \mathrm{kg}$ ) was orally administered for 2 weeks, following which, the durations of immobility were determined in a FST. The immobility durations determined in the IW groups $(0.01$, 0.1 and $1 \mathrm{~g} / \mathrm{kg}$ ) were significantly decreased, compared with the durations in the D.W. groups (Fig. 1A; P<0.05). The fluoxetine group also showed significantly decreased immobility durations, compared with the D.W. groups (Fig. 1A; $\mathrm{P}<0.05$ ).

Effect of IW on the levels of 5HT and NA in the brain. Monoamine systems have wide-ranging effects on animal behavior, and noradrenergic and serotonergic systems have long been implicated in depression (2). The reduced levels of $5 \mathrm{HT}$ or NA are considered to be involved in the underlying pathophysiology of clinical depression (15). Antidepressants elevate extracellular levels of monoamines by inhibiting their 


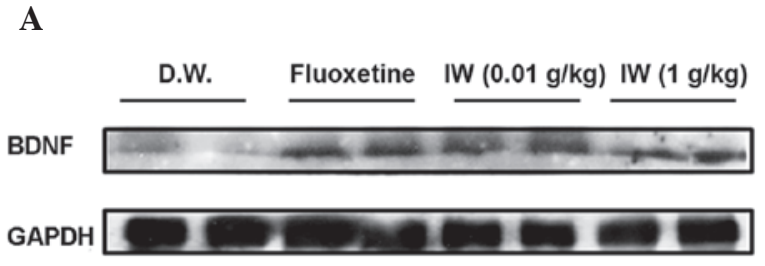

C

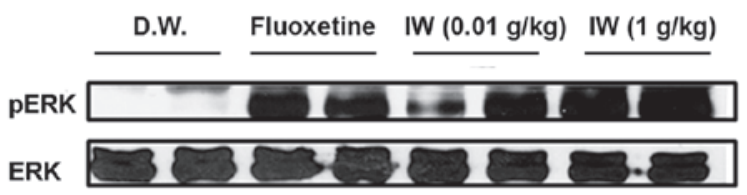

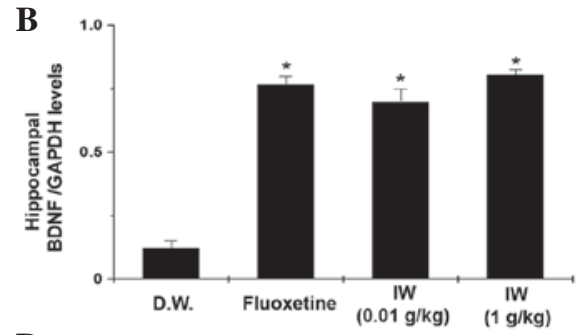

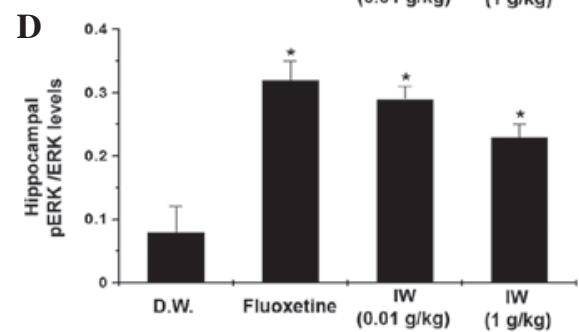

Figure 3. Effect of IW on the expression levels of BDNF and pERK in the hippocampus. Protein (A) expression and (B) quantification of BDNF. The (C) phosphorylation of ERK was analyzed using Western blotting, following which the protein levels of (D) pERK were quantitated by densitometry. Values are expressed as the mean \pm standard error of the mean, ${ }^{*} \mathrm{P}<0.05$, vs. D.W. control group. IW, Ikwitang; D.W., distilled water; ERK, extracellular signal-regulated kinase; pERK, phosphorylated ERK; BDNF, brain-derived neurotrophic factor.
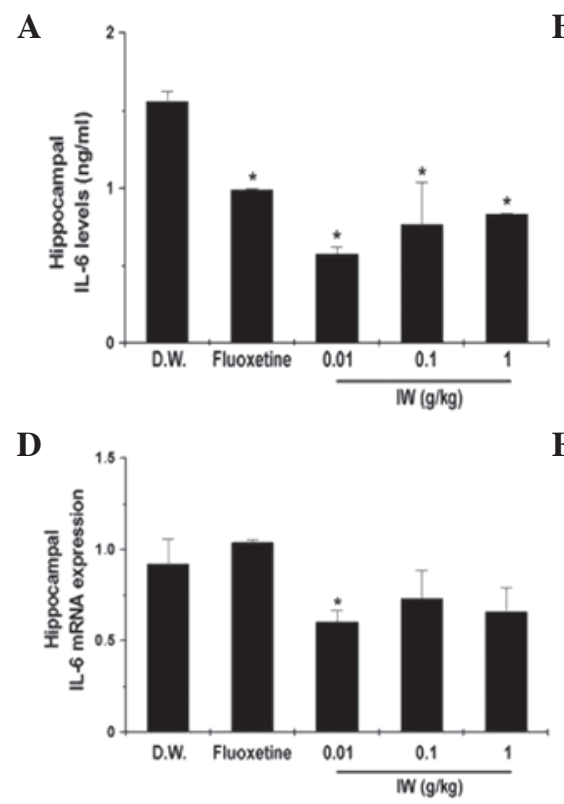

B

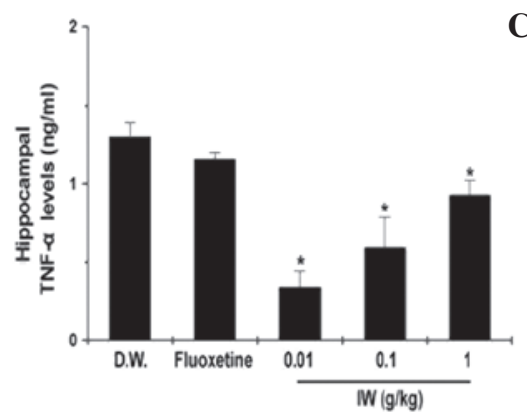

$\mathbf{E}$

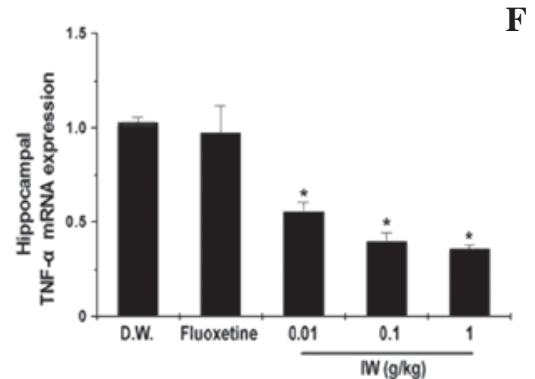

C
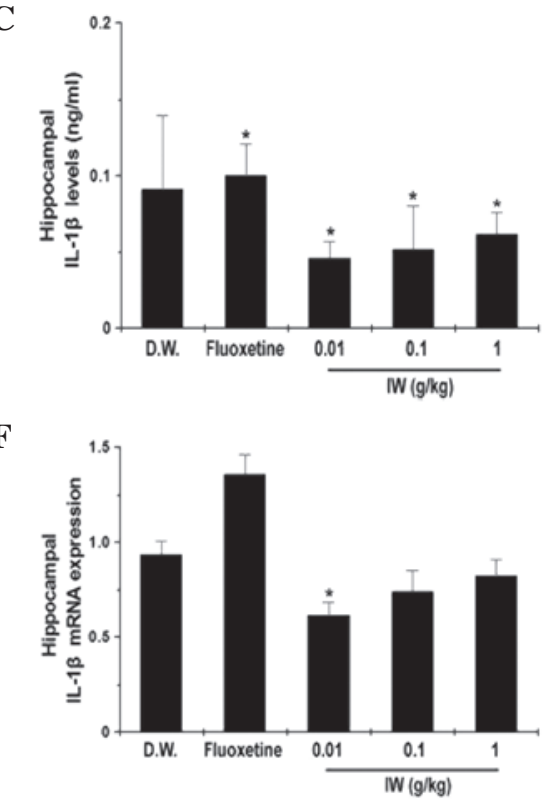

Figure 4. Effect of IW on the protein and mRNA levels of inflammatory cytokines in the hippocampus. The (A-C) protein and (D-F) mRNA levels of IL-6, TNF- $\alpha$ and IL-1 $\beta$ in the hippocampus were measured using enzyme-linked immunosorbent assay and reverse transcription-quantitative polymerase chain reaction. Values are expressed as the mean \pm standard error of the mean. "P<0.05, vs. D.W. control group. IW, Ikwitang; D.W., distilled water; IL, interleukin; $\mathrm{TNF}$, tumor necrosis factor.
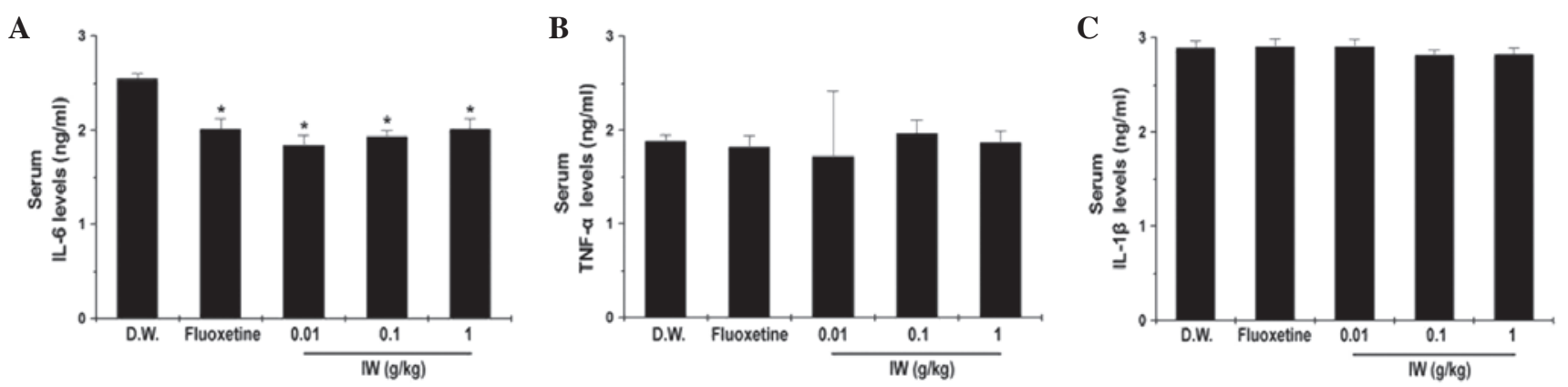

Figure 5. Effect of IW on the levels of serum inflammatory cytokines. The protein levels of (A) IL-6, (B) TNF- $\alpha$ and (C) IL-1 $\beta$ in the serum were measured using an enzyme-linked immunosorbent assay. Values are expressed as the mean \pm standard error of the mean. "P<0.05, vs. D.W. control group. IW, Ikwitang; D.W., distilled water; IL, interleukin; TNF, tumor necrosis factor. 
degradation or reuptake (3). Thus, the present study analyzed the levels of 5HT and NA in the brain following FST. As shown in Fig. 1B and $\mathrm{C}$, the levels of 5HT and NA in the IW-administered group ( $1 \mathrm{~g} / \mathrm{kg})$ were significantly increased, compared with those in the D.W.-administered group (Fig. 1B and $\mathrm{C} ; \mathrm{P}<0.05)$.

Effect of IW on hippocampal mRNA levels of ER- $\beta$. ER- $\beta$ has a beneficial effect on depression (16), therefore, the present study investigated whether the antidepressant effect of IW was associated with the expression of ER- $\beta$. The administration of IW $(0.01 \mathrm{~g} / \mathrm{kg})$ significantly increased the mRNA expression of ER- $\beta$, compared with the D.W. group.(Fig. 2, P<0.05).

Effect of IW on the protein levels of hippocampal BDNF and $p E R K$. Reduced the levels of BDNF and pERK in response to stress can lead to the impaired neurogenesis and depressive symptoms (17-20). The protein levels of BDNF in the IW groups were higher than those of the control groups (Fig. 3A and $\mathrm{B} ; \mathrm{P}<0.05)$. The protein levels of $\mathrm{pERK}$ in the IW groups were also higher than the levels in the control groups (Fig. 3C and $\mathrm{D}, \mathrm{P}<0.05)$.

Effect of IW on the protein and mRNA levels of hippocampal inflammatory cytokines. The overexpression of pro-inflammatory cytokines, including IL- 6 , TNF- $\alpha$, and IL-1 $\beta$, results in autoimmune or inflammatory reactions in depression (9). The protein levels of IL- 6 , TNF- $\alpha$ and IL- $1 \beta$ were significantly decreased by IW administration in the hippocampus (Fig. 4A-C; $\mathrm{P}<0.05$ ). The present study also measured the mRNA levels of IL- 6 , TNF- $\alpha$, and IL-1 $\beta$ in the hippocampus. As the shown in Fig. 4D-F, IW administration significantly decreased the mRNA levels of IL- 6 , TNF- $\alpha$ and IL- $1 \beta$ $(\mathrm{P}<0.05)$.

Effect of IW on the levels of serum inflammatory cytokines. Pro-inflammatory cytokines are important in the pathophysiology of depression (9). Therefore, the present study analyzed the protein levels of IL- $6, \mathrm{TNF}-\alpha$, and IL- $1 \beta$ in the serum. The levels of IL-6 in the serum were significantly decreased by IW administration, however, no significant differences were observed in the levels of TNF- $\alpha$ and IL-1 $\beta$ (Fig. 5A-C; P<0.05).

\section{Discussion}

The present study demonstrated that IW exhibited antidepressant-like effects in the FST animal model. IW significantly increased the levels of 5HT, NA, ER- $\beta$, BDNF and pERK, and decreased the duration of immobility. In addition, IW significantly decreased the levels of inflammatory cytokines levels in the hippocampus and serum.

The FST is an important tool for investigating the neurobiological mechanisms involved in antidepressant responses, and can be used for the screening of potential antidepressant agents (21). According to a previous study, monoamine has an important function in depression, and the major neurochemical process in depression is a reduction of monoaminergic functions and in the levels of 5HT and NA (22). Antidepressant drugs promote the availability of these monoamines through increasing neurogenesis and modulating the monoaminergic functions at the synapse (23). Effective antidepressants increased the levels of 5HT and NA in the brain, and decrease the duration of immobility in FSTs (24). In the present study, it was confirmed that the administration of IW for 2 weeks significantly increased the levels of 5HT and NA in the brain, and decreased the durations of immobility. Therefore, the data of the present study indicated IW as a useful antidepressant-like drug.

$17-\beta$ estradiol $\left(E_{2}\right)$ exerts its actions at the two types of classical nuclear receptors, ER- $\alpha$ and ER- $\beta$. ER- $\beta$ is predominant in stress-responsive regions of the hippocampus, the bed nucleus of the stria terminalis and the paraventricular nucleus of the hypothalamus (25). Thus, $\mathrm{E}_{2}$ may act to alter affective behaviors of rodents, in part, through activation of ER- $\beta$. In anxiety and depression-like behaviors, $\mathrm{E}_{2}$ induces protective effects through the activation of ER- $\beta$ (26). The $E_{2}$ induces slowing of serotonin clearance via activation of the ER- $\beta$ /mitogen-activated protein kinase/ERK signaling cascade pathways (27). Previous neurochemical results have suggested that ER- $\beta$-knockout mice have depleted levels of 5HT in the brain (27). In the present study, it was confirmed that IW-administration upregulated the activation of ER- $\beta$. These results suggested that the antidepressant-like effect of IW was associated with ER- $\beta$ activation.

BDNF is distributed extensively in the brain. In particular, its expression is at high concentrations in the cerebral cortex and hippocampus (28). However, exposure to stress is associated with decreased expression of BDNF (29). The levels of BDNF reduced by depression or stress are increased by administration of antidepressant in the hippocampus (29). The deletion of BDNF in adult mice produces chronic pain and symptoms of depression (30). Thus, there is an association between reduced levels of BDNF and chronic pain associated with depressive behavior. The data obtained in the present study showed that the protein levels of BDNF of IW groups were higher, compared with the protein levels of BDNF in the control groups. ERK is extensively distributed throughout the central nervous system, and the ERK pathway is involved in depression (31). The protein levels of pERK in the IW groups were higher, compared with those in the control groups. This effect of IW is similar to the mechanism of action of the antidepressant drug, fluoxetine. Therefore, these results suggested that IW has an antidepressant-like effect via activation of the BDNF/ERK signaling pathway.

Pro-inflammatory cytokines, including IL-6, TNF- $\alpha$ and IL-1 $\beta$, are involved in inflammatory processes and increase the symptoms of depression (32). IL-1 $\beta$ and IL-6 are responsible for hyperactivation of the hypothalamic-pituitary-adrenal axis and activation of the indoleamine 2,3-dioxygenase enzyme in the FST and tail suspension test (32). Patients with depression present with significantly higher levels of IL-1b, IL-6 and TNF- $\alpha$ in the brain and blood (9). Alterations in the metabolism of 5HT and NA have been associated with the potent effects of pro-inflammatory cytokines on pathways involved in the pathophysiology of depression (33). The present study showed that the levels of IL-6, TNF- $\alpha$ and IL-1 $\beta$ were significantly decreased by IW administration in the hippocampus and serum, suggesting that IW had an antidepressant-like effect due to the suppression of inflammation by IW.

According to previous reports (10), IW has anti-inflammatory effects. IW is composed of the five medicinal herbs, 
Liriopis Tuber, Rehmanniae Radix, Adenophorae Radix, Rhizoma Polygonati odorati and Saccharum nigrum. Previous studies have reported that each medicinal herb has a different effect, for example, Rehmanniae Radix has an antidepressant-like effect (12). Catalpol is a major bioactive compound of Rehmanniae Radix, and certain studies have reported that catalpol ameliorates cognitive deficits and has a neuroprotective effect (34). In addition, catalpol offers potential as a treatment for inflammation-associated neurodegenerative diseases (34). Liriopis Tuber and Adenophorae Radix have been observed to significantly reduce inflammation and hyper-responsiveness in an asthma animal model $(11,13)$. In conclusion, the present study demonstrated that IW had an antidepressant-like effect, via the BDNF signaling pathway, and suppressed inflammation. In addition, the results indicated that IW induced antidepressant-like effects through activation of the serotonin and noradrenaline systems. Therefore, it was hypothesized that IW may be used as a promising antidepressant-like drug. However, the active components of IW require isolation in further experiments, to clarify whether the components themselves may also be effective in the treatment of depression.

\section{Acknowledgements}

This study was supported by Basic Science Research Program through the National Research Foundation of Korea, funded by the Ministry of Education, Science and Technology (grant no. 2012R1A1A2A10044645).

\section{References}

1. Alfonso J, Frasch AC and Flugge G: Chronic stress, depression and antidepressants: Effects on gene transcription in the hippocampus. Rev Neurosci 16: 43-56, 2005

2. Reeves RR and Ladner ME: Antidepressant-induced suicidality: An update. CNS Neurosci Ther 16: 227-234, 2010.

3. Shively CA, Mirkes SJ, Lu NZ, Henderson JA and Bethea CL: Soy and social stress affect serotonin neurotransmission in primates. Pharmacogenomics J 3: 114-121, 2003.

4. Xu Y, Ku BS, Yao HY, Lin YH, Ma X, Zhang YH and Li XJ: Antidepressant effects of curcumin in the forced swim test and olfactory bulbectomy models of depression in rats. Pharmacol Biochem Behav 82: 200-206, 2005

5. Lee S, Jeong J, Kwak Y and Park SK: Depression research: Where are we now? Mol Brain 3: 8, 2010.

6. Ji XW, Wu CL, Wang XC, Liu J, Bi JZ and Wang DY: Monoamine neurotransmitters and fibroblast growth factor-2 in the brains of rats with post-stroke depression. Exp Ther Med 8: 159-164, 2014

7. Watanabe K, Hashimoto E, Ukai W, Ishii T, Yoshinaga T, Ono T, Tateno M, Watanabe I, Shirasaka T, Saito S and Saito T: Effect of antidepressants on brain-derived neurotrophic factor (BDNF) release from platelets in the rats. Prog Neuropsychopharmacol Biol Psychiatry 34: 1450-1454, 2010.

8. Patterson M and Yasuda R: Signalling pathways underlying structural plasticity of dendritic spines. Braz J Pharmacol 163 . 1626-1638, 2011

9. Maes M: Evidence for an immune response in major depression: A review and hypothesis. Prog Neuropsychopharmacol Biol Psychiatry 19: 11-38, 1995.

10. Go JH, Jung JH, Chang YJ, Kim HM and Chung YJ: Ikwi-tang for the treatment of allergic rhinitis as a traditional medicine. TANG 3: 37-42, 2013.

11. Lee YC, Lee JC, Seo YB and Kook YB: Liriopis tuber inhibit OVA-induced airway inflammation and bronchial hyperresponsiveness in murine model of asthma. J Ethnopharmacol 101: 144-152, 2005

12. Kang M, Shin D, Oh JW, Cho C, Lee HJ, Yoon DW, Lee SM, Yun JH, Choi H, Park S, et al: The anti-depressant effect of Nelumbinis semen on rats under chronic mild stress induced depression-like symptoms. Am J Chin Med 33: 205-213, 2005.
13. Livak KJ and Schmittgen TD: Analysis of relative gene expression data using real-time quantitative PCR and the 2(-Delta Delta C(T)) method. Methods 25: 402-408, 2001.

14. Roh SS, Kim SH, Lee YC and Seo YB: Effects of radix adenophorae and cyclosporine A on an OVA-induced murine model of asthma by suppressing to $\mathrm{T}$ cells activity, eosinophilia and bronchial hyperresponsiveness. Mediators Inflamm 2008: 781425, 2008.

15. Masi G and Brovedani P: The hippocampus, neurotrophic factors and depression: Possible implications for the pharmacotherapy of depression. CNS Drugs 25: 913-931, 2011.

16. Walf AA, Koonce CJ and Frye CA: Adult female wildtype, but not oestrogen receptor beta knockout, mice have decreased depression-like behaviour during pro-oestrus and following administration of oestradiol or diarylpropionitrile. J Psychopharmacol 23: 442-450, 2009.

17. Schmidt HD and Duman RS: The role of neurotrophic factors in adult hippocampal neurogenesis, antidepressant treatments and animal models of depressive-like behavior. Behav Pharmacol 18: 391-418, 2007.

18. Gerrits M, Westenbroek C, Koch T, Grootkarzijn A and ter Horst GJ: Increased lim-bic phosphorylated extracellular-regulated kinase 1 and 2 expression after chronic stress is reduced by cyclic 17 beta-estradiol administration. Neuroscience 142: 1293-1302, 2006.

19. Jeong HJ, Kim JH, Kim NR, Yoou MS, Nam SY, Kim KY, Choi Y, Jang JB, Kang IC, Baek NI and Kim HM: Antidepressant effect of Stillen. Arch Pharm Res 38: 1223-1231, 2015.

20. Hughes ZA, Liu F, Platt BJ, Dwyer JM, Pulicicchio CM, Zhang G, Schechter LE, Rosenzweig-Lipson S and Day M: WAY-200070, a selective agonist of estrogen receptor beta as a potential novel anxiolytic/antidepressant agent. Neuropharmacology 54: $1136-1142,2008$

21. Petit-Demouliere B, Chenu F and Bourin M: Forced swimming test in mice: A review of antidepressant activity. Psychopharmacology (Berl) 177: 245-255, 2005.

22. Zheng M, Fan Y, Shi D and Liu C: Antidepressant-like effect of flavonoids extracted from Apocynum venetum leaves on brain monoamine levels and dopaminergic system. J Ethnopharmacol 147: 108-113, 2013.

23. Delgado PL: Depression: The case for a monoamine deficiency. J C Psychiatry 61 (Suppl 6): S7-S11, 2000.

24. Kumar N, Dhayabaran D, Nampoothiri M, Nandakumar K, Puratchikody A, Lalani N, Dawood K and Ghosh A: Atypical antidepressant activity of 3,4-Bis(3,4-Dimethoxyphenyl) Furan-2,5-Dione Isolated from heart wood of cedrus deodara, in rodents. Korean J Physiol Pharmacol 18: 365-369, 2014.

25. Shughrue PJ, Lane MV and Merchenthaler I: Comparative distribution of estrogen receptor-alpha and -beta mRNA in the rat central nervous system. J Comp Neurol 388: 507-525, 1997.

26. Rocha BA, Fleischer R, Schaeffer JM, Rohrer SP and Hickey GJ: 17 Beta-estradiol-induced antidepressant-like effect in the forced swim test is absent in estrogen receptor-beta knockout (BERKO) mice. Psychopharmacology (Berl) 179: 637-643, 2005.

27. Imwalle DB, Gustafsson JA and Rissman EF: Lack of functional estrogen receptor beta influences anxiety behavior and serotonin content in female mice. Physiol Behav 84: 157-163, 2005.

28. Binder DK and Scharfman HE: Brain-derived neurotrophic factor. Growth Factors 22: 123-131, 2004.

29. Lee BH and Kim YK: The roles of BDNF in the pathophysiology of major depression and in antidepressant treatment. Psychiatry Investing 7: 231-235, 2010.

30. Heldt SA, Stanek L, Chhatwal JP and Ressler KJ: Hippocampus-specific deletion of BDNF in adult mice impairs spatial memory and extinction of aversive memories. Mol Psychiatry 12: 656-670, 2007.

31. Johnson GL and Lapadat R: Mitogen-activated protein kinase pathways mediated by ERK, JNK and p38 protein kinases. Science 298: 1911-1912, 2002.

32. Zhang X, Jin C, Li Y, Guan S, Han F and Zhang S: Catalpol improves cholinergic function and reduces inflammatory cytokines in the senescent mice induced by D-galactose. Food Chem Toxicol 58: 50-55, 2013.

33. Capuron L and Miller AH: Immune system to brain signaling: Neuropsychopharmacological implications. Pharmacol Ther 130: 226-238, 2011.

34. Chen W, Li X, Jia LQ, Wang J, Zhang L, Hou D, Wang J and Ren L: Neuroprotective activities of catalpol against CaMKII-dependent apoptosis induced by LPS in PC12 cells. Br J Pharmacol 169: 1140-1152, 2013. 